\title{
Design and Performance Evaluation of PLC Based Automation System for Strip Packaging Machine
}

\author{
D. D. Vyas ${ }^{1 *}$, D. R. Bhojani ${ }^{2}$, P. C. Gohel ${ }^{3}$ \\ ${ }^{1 *}$ Department of Electronics \& Communication Engineering, Darshan Institute of Engineering \& Technology, Rajkot, Gujarat, INDIA \\ ${ }^{2}$ Department of Electronics \& Communication Engineering, Government Engineering College, Rajkot, Gujarat, INDIA \\ ${ }^{3}$ Department of Electrical Engineering, Darshan Institute of Engineering \& Technology, Rajkot, Gujarat, INDIA
}

\begin{abstract}
Strip packaging machines are very common in pharmaceutical industries. In a conventional non-automated strip packaging machine the process of tablet drooping and strip cutting is performed using mechanical system based on cams. Basic drawback of such machines is that, mechanical parts have to be changed every time the product changes or the strip specification changes. This involves time and requires expertise. Also it involves lots of wastage in initial setting. This paper presents system automation of such strip packaging machine using programmable logic controller (PLC). As a part of solution the process of tablet dropping and strip cutting is automated. Main elements used in the proposed system include PLC, human machine interface (HMI), rotary encoders, proximity sensors and pneumatic system. Ladder diagram has been used to design system software. Field trial of proposed machine was taken for period of around two months and its performance is compared with the conventional machine. It is observed that for every new batch process as the proposed system do not need major change of mechanical parts it leads to saving of around $80 \%$ time in fitting and initial calibration. It also substantially reduces wastage of tablets and packing material and provides more precise operation compared to conventional machine.
\end{abstract}

Keywords: automation, strip packaging, packaging machines, programmable logic controller.

\section{Introduction}

Reducing profit margins, Just-In-Time (JIT) manufacturing and various quality standards have compelled manufacturing units to adopt automation and new technology. Strip packaging machine is one of the widely used machines in pharmaceutical industries particularly at units involved in bulk production of drugs. These machines are used to pack tablets or capsules in a heat sealable laminated foil (e.g. aluminum foil) as shown in Figure 1. Typical strip packaging machine is shown in Figure 2. Sealing mechanism in the machine consists of heated sealing rollers with cavities and sealing regions appropriately designed as per the item to be packed. Aluminum foils from either side is passed between the rollers and tablets to be packed are dropped in the cavities and sealed. These are then appropriately cut so as to have desired strip size. In conventional non-automated machine these major operations of dropping and cutting are executed using mechanical fixtures like cam. These machines are good if dimension of the item to be packed and size of the strip remain same. For any changes in these, allied mechanical

*Corresponding Author: e-mail: divyang.vyas@darshan.ac.in Tel-+91-98795 99686

ISSN 2320-7590

(C) 2019 Darshan Institute of Engg. \& Tech., All rights reserved parts have to be changed. Replacing mechanical parts and recalibrating the machine is an involved task that requires repeated trials and not less than few hours of work for an expert operator. Further, during production, due to mechanical slip or other reasons drift in cut position and delay/advance in tablet dropping operation is often observed. In conventional machines correction to mitigate this error cannot be applied in run-time and the machine has to be stopped. This results into loss of production time and higher wastage. Further in conventional machine the rate of production i.e. the speed of machine is adjusted manually which is not precise but based on rough estimate. Also real time information about number of tables packed, number of strips produced, etc. is not available.

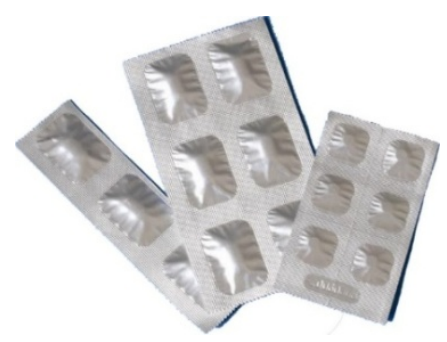

Figure 1. Tablet strips packed in aluminum foil 
This paper proposes system automation solution for the conventional strip packaging machine. Objectives of the system are: (a) to automate the process of tablet dropping and strip cutting eliminating the need of change in mechanical parts (b) to avail facility of storing multiple recipes of regular products to be packed for easy and fast operation, (c) to provide facility of run time correction in drooping and cutting operations without need of stopping the machine, (d) to automatically control rate of production on basis of desired value of tables packed per minute as entered by the operator (e) to provide HMI based user friendly operator's console and provided real time information about number of tables packed, number of strips produced, etc. The paper has been organized as follows. In Section 2 major drawbacks of conventional non-automated machine in terms of its design and operation constraints are discussed. In Section 3 architecture of proposed system is discussed. In Section 4 system software and operation flow is presented followed by experimental results in Section 5 and conclusion in Section 6.

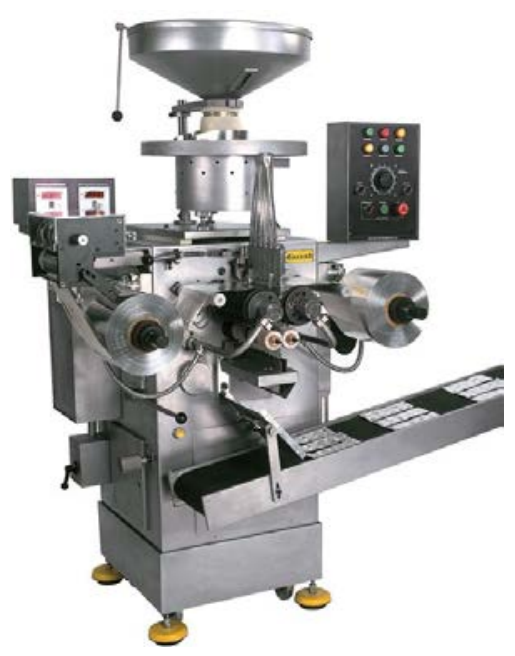

Figure 2. Typical strip packaging machine

\section{Brief on Design Drawbacks of Conventional Non- Automated Machine}

A In strip packaging machine all motions are controlled by a single induction motor. Desired movement of different mechanical parts is derived from this using appropriate coupling. Gear box, chain-gear and bevel gear arrangements are used to change speed, torque, and transmit motion. In conventional machine motor speed is controlled using induction motor drive through manual command. Further, linear motion of dropping plunger and cutting blade is achieved using appropriate cam-follower mechanism. One such example of cam design is shown in the Figure 3.

Typically such cams have numbers of toes (projections) as per desired number of cuts. Similar multi-toe cam popularly called as charging cam is used for dropping mechanism.
Release pin attached withbracket and bearing stud mechanism moving on this cam actuates cutting and dropping operation. For different type of products to be packed and different strip dimensions design of these cams changes. Mechanical fitment of each of these components is not trivial. It not only demands time and expertise but also incurs wastage of material in initial settings.

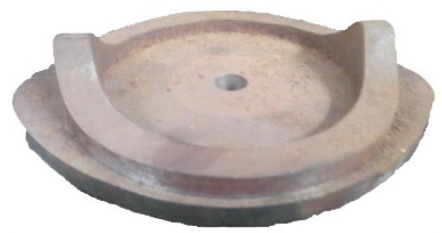

Figure. 3. Cam with two toe profile used for cut operation.

\section{Architecture of Proposed System}

In proposed design the mechanisms of dropping and cutting have been automated using PLC. Machine still derives majority of its motion from single induction motor controlled by motor drive. However, the drive is now controlled by PLC. Mechanical design of end effectors for dropping and cutting mechanism remains almost same. However, the motion in conventional machine was controlled by cam mechanism whereas in proposed design it is controlled by a PLC driven pneumatic system. Figure 4 shows system architecture at block diagram level. Major part of the system is PLC and HMI based controlling and monitoring system interfaced with different input sensors and output actuators for dropping and cutting. DVP-SA2 series PLC and DOPB07S411series HMI both from Delta Electronics is used in the design [1],[2]. Role of various input and output devices is discussed as follows.

Proximity sensor placed close to sealing roller is used to identify cavities on roller and is used to actuate tablet dropping operation through PLC. Dropping action is performed by movement of a plunger inside a specially designed multichannel funnel popularly called as chute channel. Tablets to this chute channel are sourced from bowl plate and hopper assembly. Plunger in one position allows the tablets to drop through the channels while in other position blocks it. Plunger is operated using pneumatic piston-cylinder arrangement operated using a solenoid controlled by PLC.

Rotary encoder is mounted on the shaft of sealing roller and it is used to control strip cutting operation. The sealing roller is operated by an induction motor through gear drive and other mechanical fittings. The speed of the motor and hence the sealing roller is controlled using variable frequency derive (VFD-E series from Delta Electronics) controlled by PLC [3]. Encoder mounted on the shaft of sealing roller provides 1024 pulses in one rotation and this information is used by PLC to perform cutting operation [4]. Tool used for cutting is also operated using pneumatic piston-cylinder arrangement operated using a solenoid controlled by PLC. 


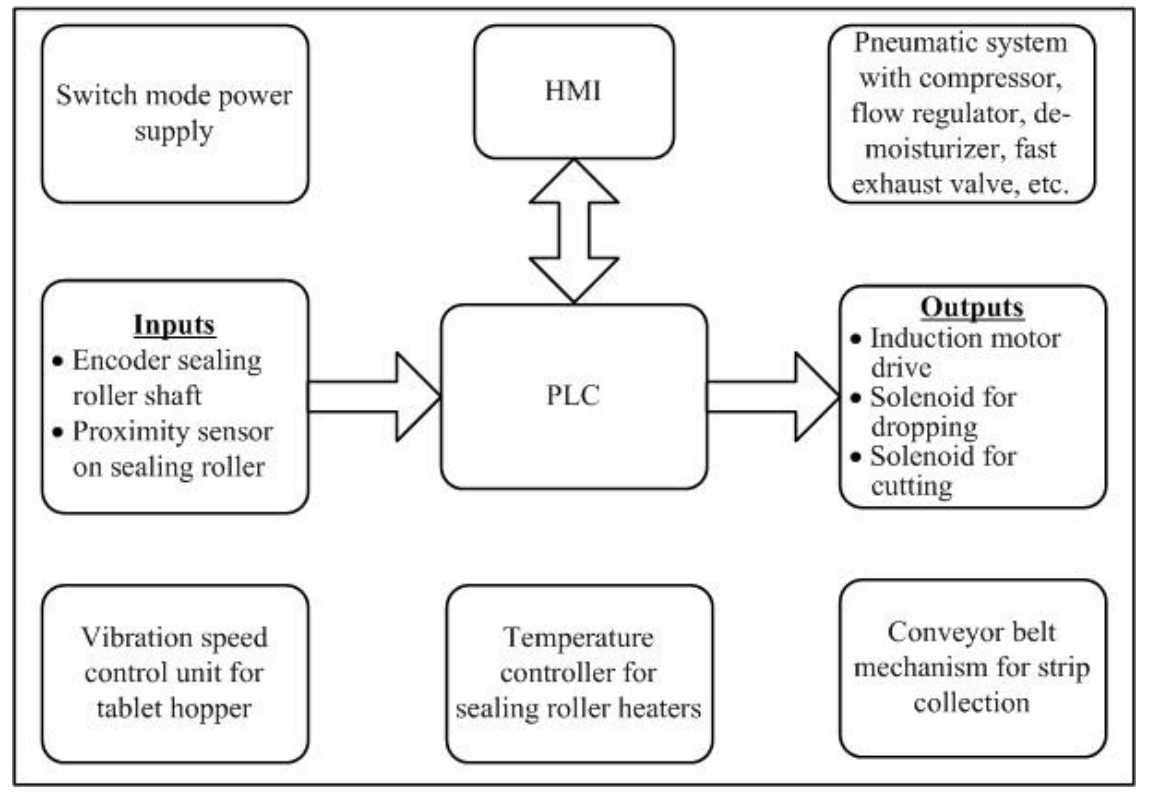

Figure 4. System Architecture

PLC as well as input and output devices that operate on $24 \mathrm{~V}$ DC supply are powered using switch mode power supply.

The system also consists of some independent control units which are discussed as follows. To support operation of all pneumatic actuators and end effectors complete pneumatic system consisting of compressor, air flow regulator, flow meter, de-moisturizer, fast exhaust value, etc. is used. Required pressure in the system is automatically controlled by the compressor.

For smooth flow of tablets into the funnel the hopper containing tablets has to be continuously vibrated. This is achieved by mounting hopper on a vibrating platform whose rate of vibration is electronically controlled by a dedicated control unit. Further, to maintain temperature of the sealing rollers dedicated temperatures controllers are used one for each roller. PT-100 type temperature sensors are used that acts as input devices for the temperature controller.

Operator's console consist of HMI, two temperature control panel meters, ON/OFF switches for HMI and PLC as well as separate switches for heater control and vibration control units, knob for controlling rate of vibration and an emergency stop button. Software on HMI allows user to configure and operate the machine. Also during production it gives information like current rate of production and total number of strip packed.

\section{Operation Flow and System Software}

The machine operates in three major states viz. initialization, calibration and production. Software related to each state involves program for operator's console (front-end code) written for HMI and program for controlling (back-end code) written for PLC. These are discussed as follows. WPLSoft is used for programming PLC whereas DOPSoft is used for programming HMI.

4.1 Initialization State: Initialization involves providing requisite features of sealing roller that will help in determining various control actions during packaging. List of major parameters to be specified is given in Table 1 . Parameters related to sealing roller in this table are illustrated in Figure 5. Reaction time in dropping and cutting mechanism refers to time lag incurred in pneumatic system and is estimated by observation.

Table 1. Parameters to be initialized.

\begin{tabular}{|l|c|}
\hline \multicolumn{1}{|c|}{ Parameter } & Units \\
\hline Circumference of sealing roller & $\mathrm{mm}$ \\
\hline Length of one cavity on sealing roller & $\mathrm{mm}$ \\
\hline Size of big sealing area where cut is applied & $\mathrm{mm}$ \\
\hline Size of small sealing area in between tablets & $\mathrm{mm}$ \\
\hline Number of cavities between & -- \\
\hline Number of cavities horizontally in one row & -- \\
\hline Number of vertical cuts on sealing roller & -- \\
\hline Reaction time of dropping mechanism & $\mathrm{ms}$ \\
\hline Reaction time of cutting mechanism & $\mathrm{ms}$ \\
\hline Product name & -- \\
\hline Recipe number & -- \\
\hline
\end{tabular}

HMI is programmed to give operator facility to enter all these details. Further, using features of recipe or batch management details of each batch process once entered is uniquely stored in HMI which can be revoked any time in 
future by product name or recipe number. During packaging operation all details related to batch process are fetched from HMI by PLC and used to perform necessary calculations that will determine required control action.

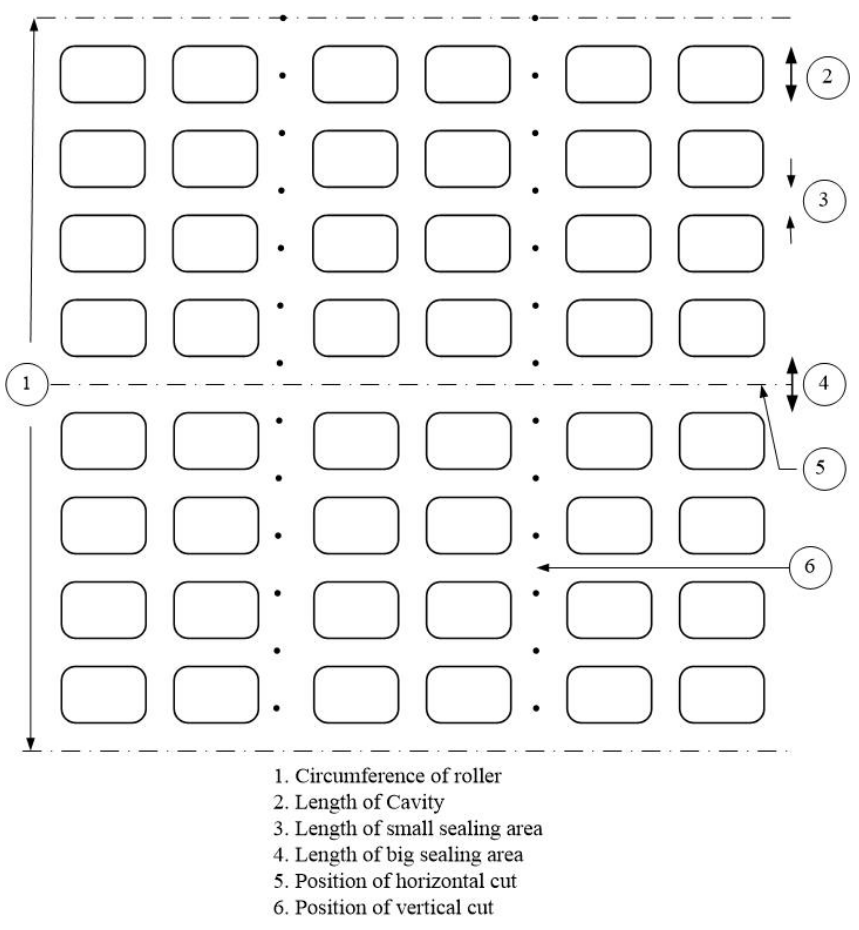

Figure 5. Various specifications of sealing roller.

4.2 Calibration: Calibration here refers to the process of defining reference position for dropping and cutting operation. From the details specified in initialization the interval or length over which dropping and cutting operation has to be performed is calculated. However, at start of batch process the initial position of the sealing roller is not known. Thus it is very likely that the dropping and cutting operation may not render the desired result. Figure 6 (a) shows example of strip before calibration.

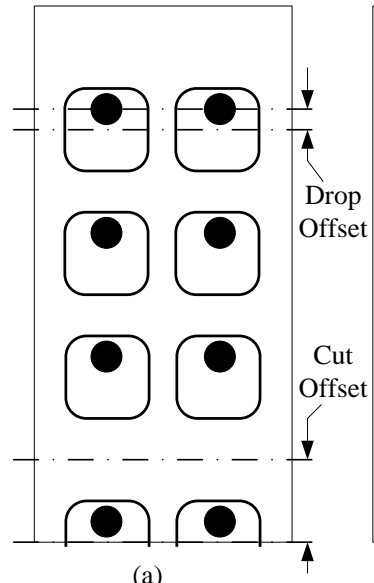

(a)

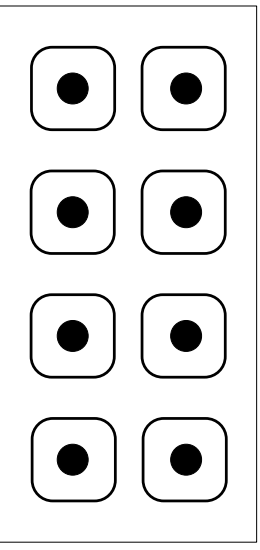

(b)
Figure. 6. (a) Strip before calibration (b) Strip after calibration.
In HMI program facility is given to select calibration operation. As shown in flowchart of Figure 7, in calibration process the machine is operated for fixed number of rotations of sealing roller, typically two. The packed strips thus obtained are manually inspected and required changes in drop and cut position is estimated and fed to machine in terms of offset in mm. Offset canbe positive or negative which will result into up or down shift of drop and cut position. The calibration process is repeated till desired result is not obtained. Figure 6(b) shows example of strip after calibration.

In addition, facility is also provided in the system to support independent checking of dropping and cutting mechanism. Reaction time of this mechanism may also be considered while deciding the offset during calibration. The program also supports simple jog operation which will only operate sealing rollers without drop or cut operation. This helps to adjust sealing foil as well as to check operation of various mechanical operations.

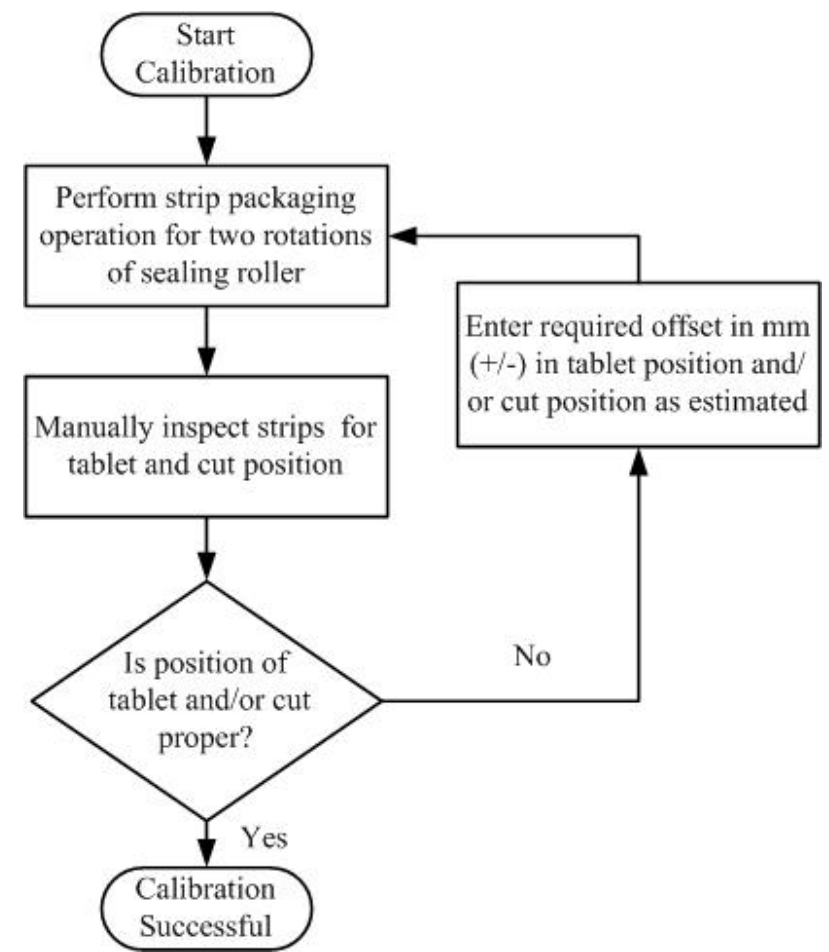

Figure 7. Flow chart representing calibration process.

4.3 Production: Once the machine is calibrated actual packing operation can be started. In HMI program facility is given to enable production i.e. to start packing operation. Operator is required to enter desired number of tables to be packed per minute. On basis of this speedof operation of the machine, i.e. rotation per minute (RPM) of sealing roller is set. Figure 8 shows HMI screen during production. On this screen other useful information like stripes packed per minutes, total tablets packed and total strips produced till now are also displayed. Facility to provide offset in drop or cut position is given to compensate for any mechanical shift during the production without stopping the machine. PLC in 
run time keeps track of these values and do needful changes in its calculations.

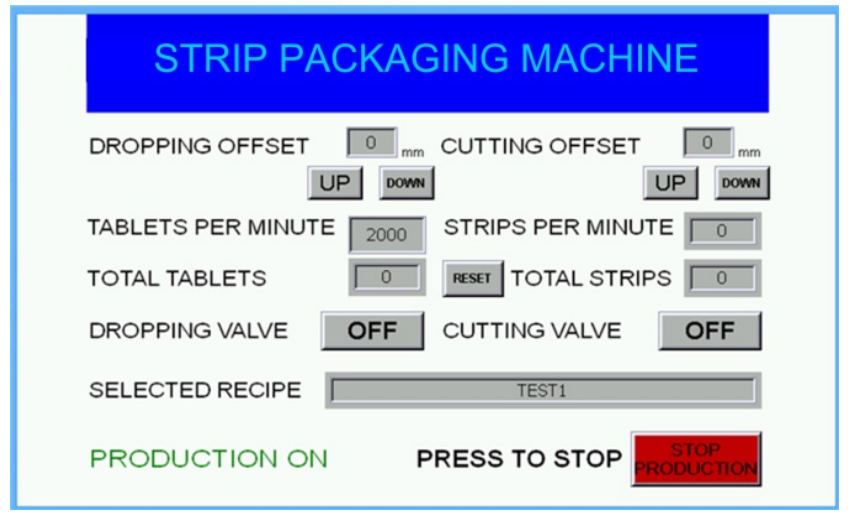

Figure 8. HMI screen during production.

\section{Performance Evaluation from Field Trials}

The proposed design was customized for M/S Ajanta Pharma Engineers. They are the leading manufacturers of conventional strip packaging machine. With their support and association field trials of automated strip packaging machine was taken and were compared with conventional machine. Table II list various observations during field trials along with supporting justifications. It was evident from the field trials that automatic strip packaging machine is certainly more convenient and accurate compared to mechanical counterpart. It allows substantial saving of time and reduction in wastage. Production rate was found to be slightly low because of finite reaction time of pneumatic improvement. However, production rate available was sufficient and hence changes in existing pneumatic system were not implemented though available. Marginal increase in the cost is due to the use of PLC, HMI, encoder and proximity sensors and pneumatic system.

Table 2.Observations and Results from Field Trials.

\begin{tabular}{|l|l|l|l|}
\hline & Details & $\begin{array}{l}\text { Conventional } \\
\text { Machine }\end{array}$ & $\begin{array}{l}\text { Automatic } \\
\text { Machine with } \\
\text { proposed } \\
\text { docion }\end{array}$ \\
\hline 1. & $\begin{array}{l}\text { Initial fitment } \\
\text { of mechanical } \\
\text { parts for new } \\
\text { batch process }\end{array}$ & $\begin{array}{l}\text { Av. time: 2 Hrs } \\
\text { Sealing roller, } \\
\text { parts in cam } \\
\text { mechanism for } \\
\text { dropping and } \\
\text { cutting has to be } \\
\text { changed }\end{array}$ & $\begin{array}{l}\text { Oninutes } \\
\text { Only sealing } \\
\text { roller has to } \\
\text { be changed }\end{array}$ \\
\hline 2. & $\begin{array}{l}\text { Calibration of } \\
\text { machine }\end{array}$ & $\begin{array}{l}\text { Av. time 45 } \\
\text { minutes } \\
\text { Requires access } \\
\text { of operator's } \\
\text { console as well } \\
\text { as mechanical } \\
\text { compartment }\end{array}$ & $\begin{array}{l}\text { Av. time 10 } \\
\text { minutes } \\
\text { Requires } \\
\text { access of only } \\
\text { operator's } \\
\text { console. }\end{array}$ \\
\hline
\end{tabular}

\begin{tabular}{|c|c|c|c|}
\hline 3. & $\begin{array}{l}\text { Wastage during } \\
\text { calibration }\end{array}$ & $\begin{array}{l}60 \% \text { less wastage } \\
\text { machine compare } \\
\text { conventional mac } \\
\text { number of iteratic }\end{array}$ & $\begin{array}{l}\text { automated } \\
\text { to } \\
\text { ine as less } \\
\text { s are required }\end{array}$ \\
\hline 4. & $\begin{array}{l}\text { Precision in cut } \\
\text { and drop } \\
\text { operations } \\
\text { during } \\
\text { production }\end{array}$ & $85 \%$ & $98 \%$ \\
\hline 5. & $\begin{array}{l}\text { Av. Production } \\
\text { time lost due to } \\
\text { adjustment } \\
\text { against } \\
\text { mechanical slip } \\
\text { (calculated for } \\
\text { batch of } 1 \text { Lac } \\
\text { tablets at rate } \\
\text { of } 500 \\
\text { tablets/min. } \\
\text { packaging } \\
\text { speed) }\end{array}$ & $\begin{array}{l}\text { Av. } 7 \text { min per } \\
\text { hour } \\
\text { Needs to open } \\
\text { mechanical } \\
\text { compartment } \\
\text { and } \\
\text { appropriately set } \\
\text { mechanical parts } \\
\text { \& subsequent } \\
\text { trials }\end{array}$ & $\begin{array}{l}-- \\
\text { Happens in } \\
\text { run time } \\
\text { through } \\
\text { operator's } \\
\text { console }\end{array}$ \\
\hline 6. & Operator & $\begin{array}{l}\text { Operator with } \\
\text { expertise in } \\
\text { mechanical } \\
\text { fitting is } \\
\text { required to } \\
\text { operate the } \\
\text { machine }\end{array}$ & $\begin{array}{l}\text { Operator with } \\
\text { average skills } \\
\text { can operate } \\
\text { the machine }\end{array}$ \\
\hline 7. & $\begin{array}{l}\text { Maximum } \\
\text { production rate } \\
\text { with faithful } \\
\text { performance }\end{array}$ & 900 tables/min & $\begin{array}{l}800 \\
\text { tables/min } \\
\text { Limited by } \\
\text { operation of } \\
\text { pneumatic } \\
\text { system }\end{array}$ \\
\hline 8. & Cost & \multicolumn{2}{|c|}{$\begin{array}{l}\text { Automatic machine is around } \\
20 \% \text { costly compared to } \\
\text { conventional mechanical machine }\end{array}$} \\
\hline
\end{tabular}

\section{Conclusion}

Design of system automation for conventional strip packaging machine has been proposed. Proposed design is based on PLC and helps to remove dependency on product specific mechanical parts like cam assembly in the machine which are required to be changed for every new batch process. During the field trials it has been observed that the proposed design help to reduce time required for initial fitting and calibration by $80 \%$ and also reduces wastage incurred in the process. Provision to compensate for any drift in cut or drop position in run time without stopping the machine also helps to reduce overall time of production. Further, automated machine is more convenient to operate and can be handled even by operator with limited skills. The advantages achieved through the proposed design quite easily justify the 
marginal increase in the cost. As a part of future work the system for No Fill Detection (NFD) can be introduced in the system which will further eliminate need of manual inception of strips produced.

\section{References}

1. Delta, PLC DVP-SA2 Series Installation Instructions, http://www.deltaww.com/filecenter/Pro ducts/download/06/060301/Manual/DELTA_IAPLC_DVP-SA2_I_TSET_20140430.pdf, 2014.
2. Delta, Touch Panel HMI DOP-B Series Installation Instructions, http://www.deltaww.com/filecenter/ Products/download/06/060302/Manual/DELTA_IAHMI_DOP-B07S411-S401K-S411K_Q_TC-ENSC-TUR_20160714.pdf, 2016.

3. Delta, Sensorless Vector Controlled AC Drive VFDE Series, http://www.deltaww.com/filecenter/ Products/download/06/060101/Manual/DELTA_IAMDS_VFD-E_UM_EN_20160516.pdf, 2016

4. Autonics, Incremental Rotary Encoder E50S Series, http://www.autonicsonline.com/image/pdf/E50S.pdf, 2015.

\section{Biographical notes}

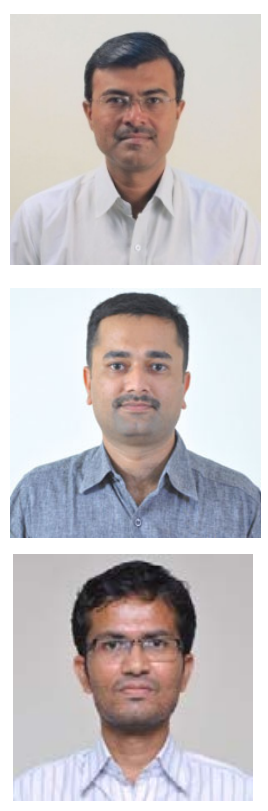

D. D. Vyas has received his Ph.D. from Saurashtra University in Electronics and Communication Engineering and M.Tech. from IIT, Bombay in Electronic Systems. He is Professor and Head, Department Electronics \& Communication Engineering at Darshan Institute of Engineering \& Technology, Rajkot, Gujarat, India. He has published 30 papers in national and international journals and conferences of repute. He has authored 2 books and published a patent under IP India. He is fellow at IETE and Chartered Engineer at IE. His research interest includes Embedded Systems, Industrial automation, Control Systems and Digital Signal Processing.

D. R. Bhojani has received his Ph.D. from J J T University in Electronics \& Communication Engineering and M. E. from L D College of Engineering in Communication Systems. He is working as Asst. Prof. in Department of Electronics \& Communication Engineering at Government Engineering College, Rajkot, Gujarat, India. He has published more than 16 international publications, one Indian patent and two books. His research interest is in the domain of Image and Video Processing, Industrial Automation, Embedded Systems.

P. C. Gohel is working as Laboratory Assistance at Department of Electrical Engineering at Darshan Institute of Engineering \& Technology, Rajkot, Gujarat, India. He has working experience of 12 years. His areas of interest are Solar and Industrial Automation. 